\title{
Centrifugal Compressor Tip Clearance and Impeller Flow
}

\author{
Ahti Jaatinen-Värri ${ }^{1 *}$, Jonna Tiainen ${ }^{1}$, Teemu Turunen-Saaresti ${ }^{1}$, Aki Grönman ${ }^{1}$, Alireza Ameli ${ }^{1}$, Abraham \\ Engeda $^{2}$, Jari Backman ${ }^{1}$ \\ ${ }^{1}$ Laboratory of Fluid Dynamics, LUT School of Energy Systems, Lappeenranta University of Technology, Finland \\ ${ }^{2}$ Turbomachinery Laboratory, Department of Mechanical Engineering, Michigan State University, USA
}

\begin{abstract}
Compressors consume a considerable portion of the electricity used in the industrial sector. Hence, improvements in compressor efficiency lead to energy savings and reduce environmental impacts. The efficiency of an unshrouded centrifugal compressor suffers from leakage flow over the blade tips. The effect of tip leakage flow on the passage flow differs between the full and splitter blade passages. In this paper, the differences in the flow fields between the full and splitter blade passages are studied numerically in detail. An industrial high-speed compressor with a design pressure ratio of 1.78 is modelled. Numerical studies are conducted with six different tip clearances and three different diffuser widths. The results show that increasing tip clearance considerably increases the reversed flow into the impeller with an unpinched diffuser. The reversed flow then partly mixes into the flow in the same blade passage it entered the impeller and the rest migrates over the blade, mixing with the tip clearance flow. Furthermore, as the reversed and clearance flow mix into the wake, the wake is weakened. As pinch reduces both the reversed flow and clearance flow, the passage wakes are stronger with pinches. However, the pinch is beneficial as the losses at the impeller outlet decrease.
\end{abstract}




\section{Introduction}

Centrifugal compressors are commonly used in the process, oil, and gas industries, combustion engine turbochargers and wastewater treatment plants. In general, compressors of all types consume a vast amount of energy, e.g. in the EU the motors operating the compressors consume $25 \%$ of the electricity consumed by the industrial sector [1], and the energy costs of compressor processes can be $75 \%$ or more of the life-cycle costs [2]. Hence, improvements in compressor efficiency lead to savings in consumed energy and life cycle costs [3].

The performance of the unshrouded centrifugal compressor suffers from leakage flow over the blade tips. The tip leakage flow is a consequence of the pressure difference over the blade tip. The effect of the tip leakage flow on the impeller flow field depends on the impeller geometry, e.g. the size of the tip clearance affects the strength of the tip leakage flow.

It is well documented that the stage efficiency and pressure ratio decrease when the tip clearance is increased [4-6]. A more recent study [7] showed that different centrifugal compressors react differently towards the tip clearance. The slope of the efficiency curve (i.e. how much the efficiency drops with respect to increasing tip clearance) varied from 0.2 to 1.0 meaning that for some compressors the efficiency drop is fivefold. For the most part it is still unclear how the different design parameters affect the compressor efficiency.

Backman et al. [8] tested several different compressors and found that compressors with a vaneless diffuser, a pinched vaneless diffuser, lower overall efficiency or lower diffusion ratio in the impeller are less sensitive to an increase in the tip clearance. However, they also concluded that their test results did not verify the interdependency of the trends to find out the exact reason for the phenomenon.

What is known is that a large relative tip clearance causes a strong tip leakage flow resulting in strong secondary flow patterns and large mixing losses [9]. Also, a low blade loading in the inducer results in a weak tip leakage flow [9, 10], whereas a high blade loading results in a stronger tip leakage flow [11]. In addition , the actual blade design has an effect on the tip leakage flow. Flow inside an impeller with a backsweep was more sensitive to the effects of the tip clearance than an impeller with radial blades [12].

Several researchers have investigated the effect of tip leakage flow on the impeller flow field in different compressor geometries. Schleer et al. [10] as well as Buffaz and Trébinjac [13] observed that the tip leakage vortex moves upstream with a reducing mass flow rate so that the vortex trajectory is perpendicular to the blade leading edge near the stall.

The research group at ETH Zürich observed both experimentally and numerically that the interaction of the tip leakage and passage flows differs between the full and splitter blade passages [10,11, 14, 15]. The tip leakage vortex is shed when the tip leakage jet is stopped and separated from the wall, and turned backward by the passage flow [10]. Furthermore, the tip leakage vortex of the full blade interacts with the non-rotating flow entering the impeller, whereas the tip leakage vortex of the splitter blade interacts with the rotational flow inside the impeller.

The interaction of the tip clearance vortex with the rotating flow is more intense, and the low momentum, high loss region on the suction side of the splitter blade migrates towards the middle of the blade passage. The same region on the suction side of the full blade remains closer to the blade [14]. Therefore, the flow field on the suction side of the splitter blade is less uniform than on the suction side of the full blade. A similar phenomenon is observed also by Wang et al. [16], and the present authors [17], who noticed higher entropy on the suction side of the splitter blade than on the suction side of the full blade.

Bousquet et al. [18] found that the intense full blade leakage flow shifts the low meridional velocity region at the impeller exit towards to the splitter blade pressure side both in design and near stall conditions. On the contrary, the low meridional velocity region in the passage between the splitter blade suction side and the full blade pressure side is located nearer the splitter blade suction side due to the weaker leakage flow over the splitter blade.

Also according to Schleer and Abhari [14], at the impeller exit, the low meridional velocity region is closer to the suction side of the blade at the lower clearance and when the clearance is increased, the low meridional velocity region is sifted towards the middle of the channel. Furthermore, the low meridional velocity region is larger at the suction side of the splitter blade.

Tang et al. [19] studied numerically a small (impeller outlet diameter roughly $50 \mathrm{~mm}$ ) centrifugal compressor with a real gas as a working fluid. The behaviour of flow fields with increasing tip clearance was similar to those found with larger impellers. The increased leakage grew the size of the slow flow region and it moved from the suction side of the blade towards the centre of the channel. The main flow near the pressure side of the blade was compressed and accelerated. The flow non-uniformity increased and the efficiency decreased.

Despite the location of the wake at the impeller outlet, one goal in the impeller design is to reduce losses. The flow field at the impeller exit was previously made more uniform by the inverse design method [11]. There were three differences between the inverse designed impeller and the conventional impeller. In the inverse designed impeller: 1) the fore-loaded blade loading distribution was used at the shroud and the aft-loaded distribution at the hub of the full blade, 2) loading distribution on the splitter blade was similar to that on the full blade, and 3) the hub of the blade led the tip in the direction of rotation at the trailing edge. 
The leading edge of the splitter blade was not as radial as in the high-speed applications. As a result, the tip leakage flow over the full blade did not only end up on the suction side of the splitter blade but it was split between the full and splitter blade passages. In addition, there was a marked reduction in the strength of the clearance flow in the mid-section of the full blade in the inverse design. As a result, the flow field at the impeller exit was more uniform, and the flow patterns in the two blade passages were similar. Consequently, the impeller efficiency was 1-1.5\% higher with the inversely designed impeller

In order to improve the compressor performance, the mechanism of the loss formation needs to be studied in detail. In this paper, the effect of the tip clearance on the impeller flow is studied numerically. Six different relative tip clearances are modelled with three different vaneless diffusers. The vaneless diffusers vary only with the diffuser width, so that the relative diffu ser width $b /\left(b_{2}+t_{2}\right)$ is varied from 1.00 to 0.85 . The mass balance within the impeller is studied to see how the tip clearance flows over the splitter and full blade and the flow distribution in the two channels vary with the varying tip clearance. Also, the flow fields in the impeller are studied to see how the loss generation in the impeller behaves with the changing tip clearance.

\section{Studied designs}

The modelled compressor is an industrial high-speed compressor with a design pressure ratio of 1.78 and specific speed of 0.8 . The impeller is unshrouded and has seven full and seven splitter blades with a $40^{\circ}$ backsweep. The different parallel wall vaneless diffusers varying in diffuser width were modelled. The studied diffuser widths $b /\left(b_{2}+t_{2}\right)$ were: $1.00,0.90$ and 0.85 . Previously, it was found out that if the diffuser width was further reduced, the performance of the compressor started to deteriorate [17].

The pinch was implemented at a radius ratio $r_{2} / r_{2}$ of 1.005 , and the diffuser outlet radius ratio $r_{3} / r_{2}$ was 1.68 . A schematic view of the diffuser is shown in Fig. 1. The same compressor and diffuser setups have been previously used to study the diffuser flow fields both numerically and experimentally [17, 20-24]. However, the tip clearance and impeller flow were not studied.

Each vaneless diffuser was modelled with six different relative tip clearances $t_{2} / b_{2}$, varying from 0.026 to 0.155 . The changes in tip clearance were done similarly as in the experiments, by translating the shroud side casing in the axial direction. Translation of the casing in the axial direction only changes the axial clearance at the impeller outlet whilst the radial clearance at the impeller inlet remains constant.

The pinch was implemented only at the shroud, as this has been found to be a better option than to pinch from the hub side or both the hub and shroud side [22, 23]. As the pinch is only

implemented on the shroud side, and the absolute amount of pinch was kept constant for each clearance, the diffuser width slightly increased as the tip clearance was increased. Based on previous studies, a relatively small change in the diffuser width does not considerably affect the compressor performance [20]. A summary of the modelled cases

is presented in Table 1 .

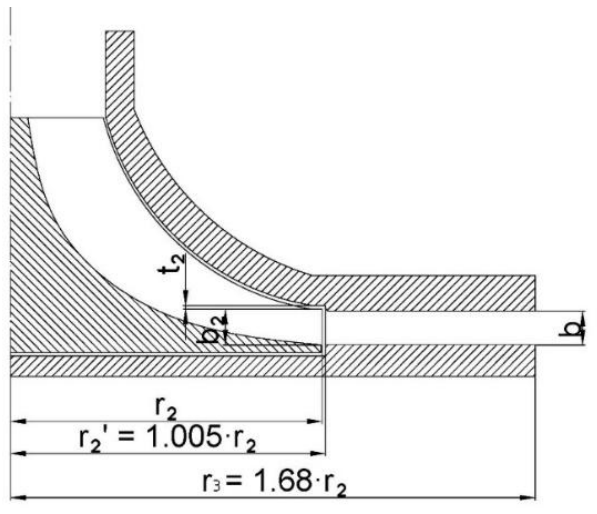

Fig. 2. A schematic view of the flow path and pinch.

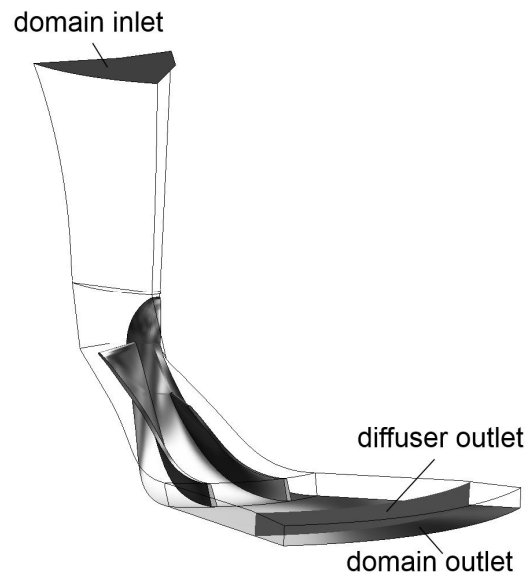

Fig. 1. The computational domain. 


\section{Numerical methods}

ANSYS CFX was used as a flow solver. As the impeller consists of full and splitter blades, the domain consists of two blade passages, and corresponding sections of the inlet cone and the vaneless diffuser were modelled as shown in Fig. 2. The periodic boundary conditions were set in the middle of the blade passages so that the blades are inside the computational domain. To save computational resources, the volute was not modelled. As the volute was omitted, only a single blade passage could be modelled. The actual vaneless diffuser outlet is shown in Fig 2. A single operating point was modelled for each case, namely the design operating point of the compressor.

The vaneless diffuser is a parallel wall, and the exit section between the diffuser outlet and computational domain outlet has a constant cross-sectional flow area. The approach was chosen to ensure that the outlet boundary would not affect the results at the diffuser outlet. A similar approach was also used by Oh and Agrawal [25] and Oh et al. [26], and the present authors in their previous study [17].

The turbulence was modelled with the $k-\omega$-SST turbulence model. The non-dimensional wall distance was below unity in most of the surfaces. Second order discretization methods were used. The total pressure and temperature were given as boundary conditions at the domain inlet and mass flow was given as a boundary condition at the domain outlet. The domain inlet and outlet are shown in Fig. 2. The total inlet pressure was set at 96 $\mathrm{kPa}$, temperature $288.8 \mathrm{~K}$. The exact mass flow cannot be disclosed, but it was set to correspond the design mass flow. Frozen rotor interface was used between the stationary and rotational zones.

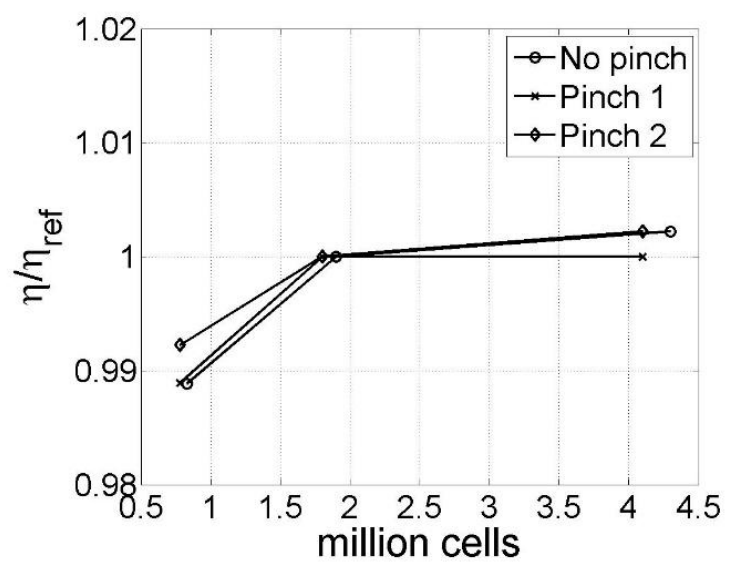

Fig. 3. Grid dependency.
Table 1. Studied designs.

\begin{tabular}{|c|c|c|c|}
\hline & $\begin{array}{l}\text { Relative tip } \\
\text { clearance } \\
t_{2} / b_{2}\end{array}$ & $\begin{array}{c}\text { Relative } \\
\text { diffuser } \\
\text { width } \\
b /\left(b_{2}+t_{2}\right)\end{array}$ & $\begin{array}{c}\text { Diffuser } \\
\text { width vs. } \\
\text { blade } \\
\text { height } \\
b / b_{2}\end{array}$ \\
\hline \multirow[t]{6}{*}{ Unpinched } & 0.026 & 1.000 & 1.026 \\
\hline & 0.052 & 1.000 & 1.052 \\
\hline & 0.077 & 1.000 & 1.077 \\
\hline & 0.103 & 1.000 & 1.102 \\
\hline & 0.129 & 1.000 & 1.129 \\
\hline & 0.155 & 1.000 & 1.155 \\
\hline \multirow[t]{6}{*}{ Pinch 1} & 0.026 & 0.899 & 0.923 \\
\hline & 0.052 & 0.902 & 0.948 \\
\hline & 0.077 & 0.904 & 0.974 \\
\hline & 0.103 & 0.907 & 1.000 \\
\hline & 0.129 & 0.909 & 1.026 \\
\hline & 0.155 & 0.911 & 1.052 \\
\hline \multirow[t]{6}{*}{ Pinch 2} & 0.026 & 0.849 & 0.871 \\
\hline & 0.052 & 0.853 & 0.897 \\
\hline & 0.077 & 0.856 & 0.923 \\
\hline & 0.103 & 0.860 & 0.948 \\
\hline & 0.129 & 0.863 & 0.974 \\
\hline & 0.155 & 0.866 & 1.000 \\
\hline
\end{tabular}

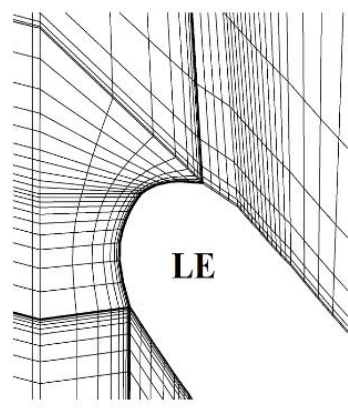

a)

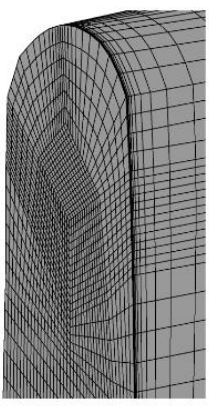

b)

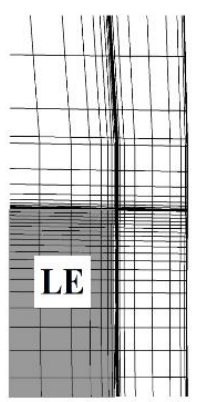

c)
Fig. 4. Mesh a) around the blade leading edge, b) on the blade surface at the leading edge, and c) in the tip gap near the leading edge in spanwise direction. 


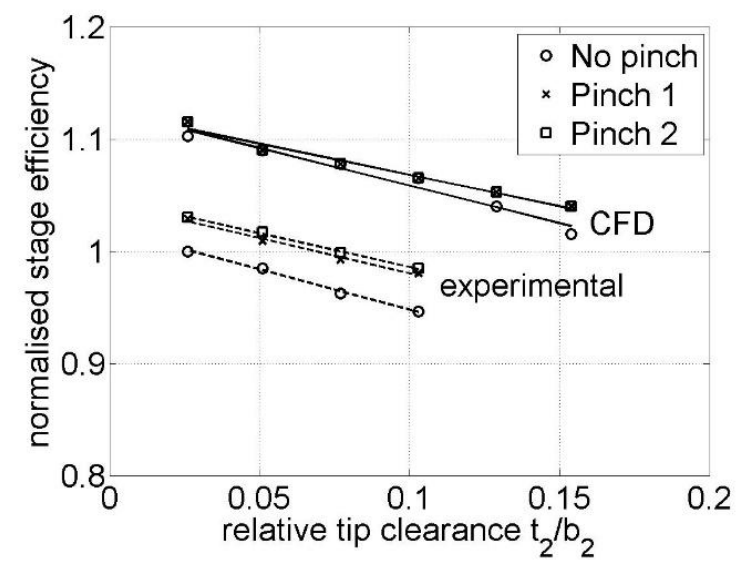

Fig. 5. Measured and modelled stage efficiency.

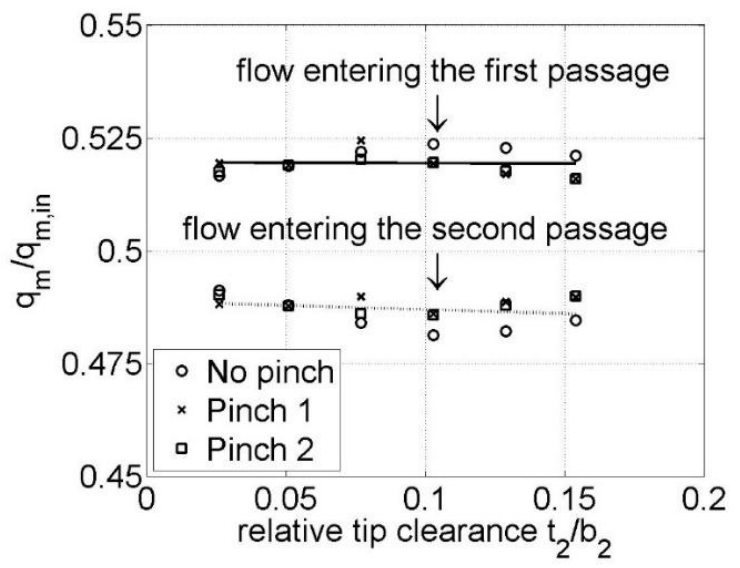

Fig. 7. Mass flows entering the blade passages.

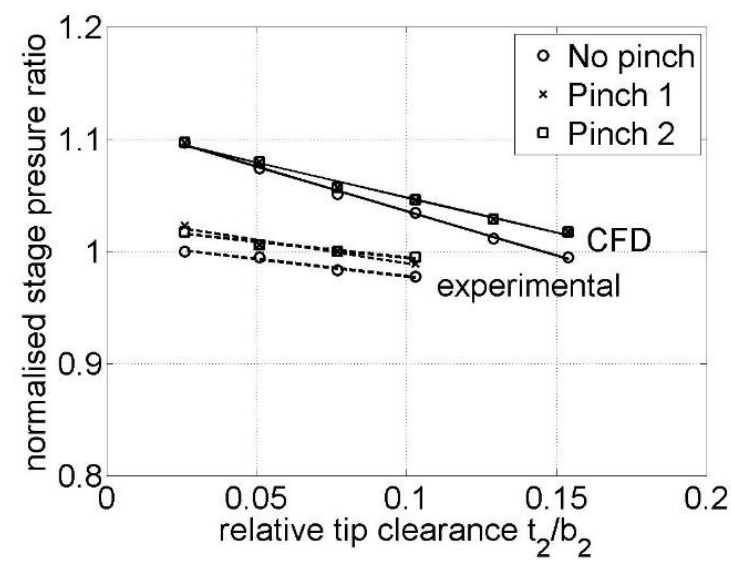

Fig. 6. Measured and modelled stage pressure ratio.

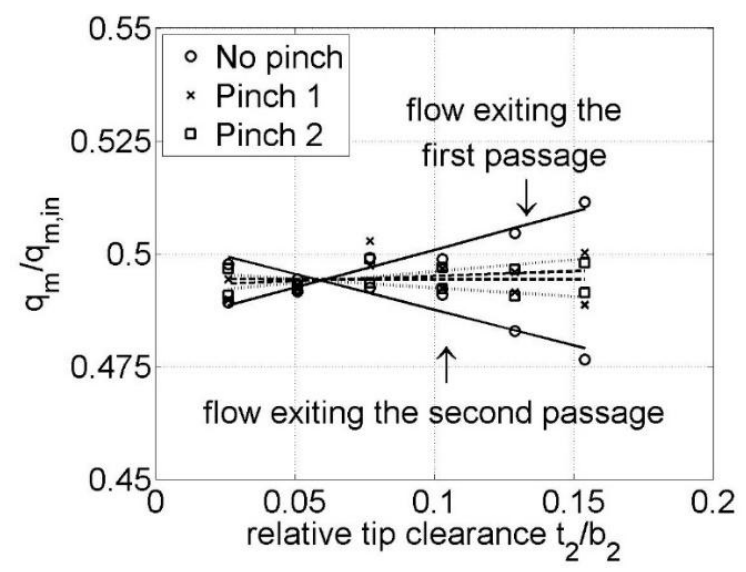

Fig. 8. Mass flows exiting the blade passages.

\subsection{Grid dependency}

A grid dependency check was performed. Like the actual simulations, also the grid dependency check was performed in a single operating point, namely the compressor design operating point. Each diffuser was modelled with the second smallest tip clearance $\left(t_{2} / b_{2}=0.052\right)$ with three different grids. The unpinched diffuser was modelled with grids that had approximately 0.83 , 1.9, and 4.3 million cells and the two pinched diffusers were modelled with grids that had approximately $0.78,1.8$, and 4.1 million cells. The difference in the cell numbers is that due to the pinch, there was no need to carry the tip clearance mesh in the spanwise direction into the diffuser. Fig. 3 shows the efficiency with respect to the cell number. The efficiencies, calculated with mass flow averaged values, are normalised with the efficiency of the grid consisting of 1.9 million cells. From the figure it can be seen that the efficiency does not change when the number of cells is increased from 1.8/1.9 million. Therefore, it is concluded that the 1.9 million cells is sufficient to produce grid independent results, especially as increasing the cell number to 4.1/4.3 million increased the computational time by $76 \%$.

The mesh is structured and has a H topology. The tip gap has 15 cells in the spanwise direction, and the mesh is denser close to the walls. The number of cells in the tip gap does not change with the varying tip clearance. The mesh around the blade leading edge, on the blade surface at the leading edge, and in the tip gap near the leading edge in spanwise direction is shown in Fig. 4.

\subsection{Comparison with experiments}

The modelled stage efficiency and pressure ratio are compared to measured ones in Figs. 5 and 6 . The efficiency and pressure 
ratio are normalised with the measured efficiency and pressure ratio with the smallest tip clearance. The measurement set up and results have been published in detail in previous papers [20, 21, 23].

The CFD somewhat overestimates the efficiency and pressure ratio. There are two main reasons for this. Firstly, the compressor was modelled without the volute, so the efficiency and pressure ratio are calculated with the diffuser exit values. On the other hand, in the experiments, the compressor outlet values were defined at the discharge pipe, after the volute and exit cone, causing an additional pressure loss in the experimental results, which leads to somewhat lower efficiency in the experiments. Secondly, it is widely known that the commonly used two-equation models, such as the $k-\omega$-SST used in this study, are incapable of predicting all losses in such a complex flow. However, despite the shortcoming, the two-equation models are widely accepted and their accuracy is deemed adequate. Most importantly, the trend of the efficiency and pressure ratio with respect to the increasing tip clearance is predicted very well.

\section{Mass flow within the impeller}

In this section, the mass flows within the impeller are discussed. As the impeller consists of full and splitter blades, the domain consists of two blade passages. For convenience, the two blade passages are referred to as the first and the second passage in the text. The first passage is the one which is between the full blade suction side and splitter blade pressure side and the second passage is between the splitter blade suction side and full blade pressure side. That is, the first channel is the first with respect to

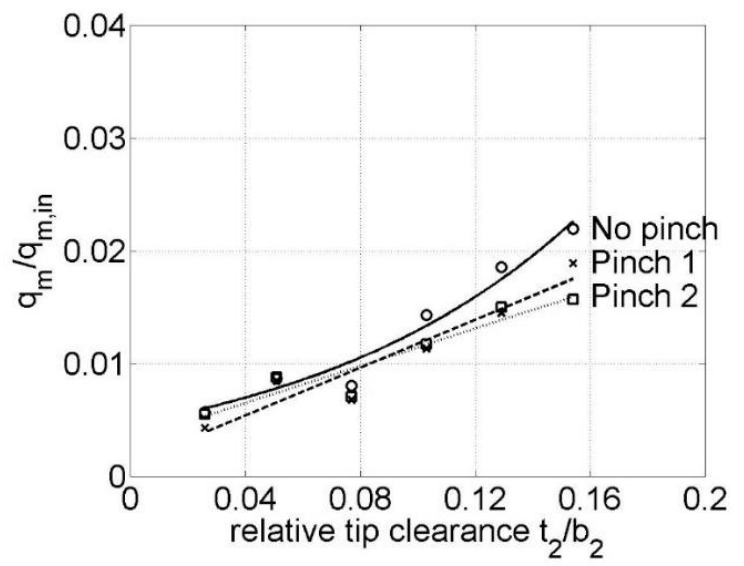

Fig. 9. Reversed flow at the impeller outlet in the first passage.

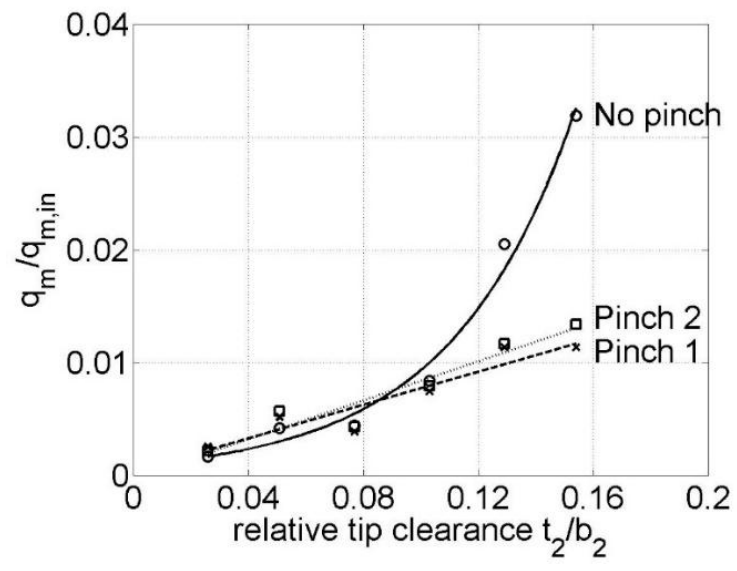

Fig. 10. Reversed flow at the impeller outlet in the second passage.

the direction of rotation. Furthermore, the mass flows are presented relative to the mass flow entering the impeller.

The relative mass flows entering and exiting the blade passages are shown in Figs. 7 and 8, respectively. The mass flows in Figs. 7 and 8 do not account for the tip leakage flows, hence they are the one-dimensional flows entering and exiting the impeller through the flow path. Even though there seems to be minimum and maximum values for flow entering the impeller at the relative clearance of $10 \%$, the difference is so small, that in this research it cannot be concluded whether it is a real phenomenon or due to the accuracy. Therefore, it can be concluded that the increasing tip clearance does not considerable affect how the incoming 


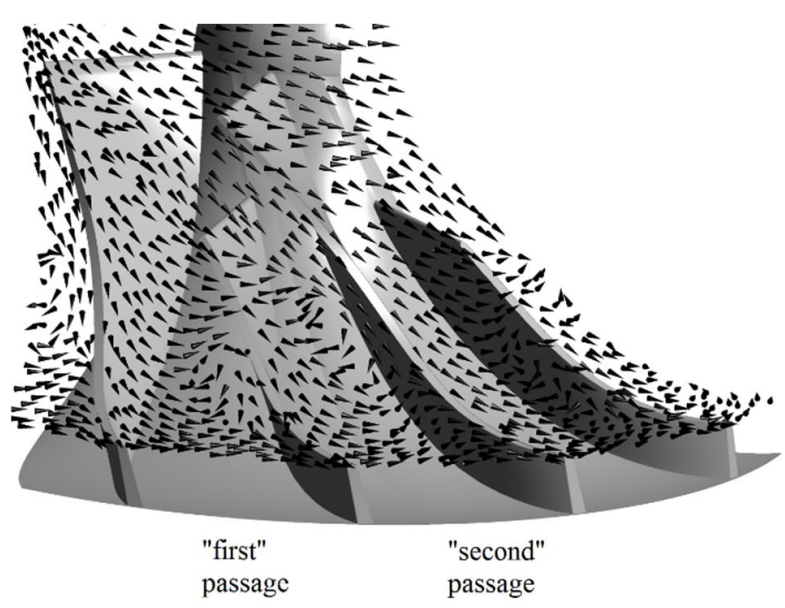

Fig. 11. Velocity vectors in the unpinched case with the largest tip clearance.

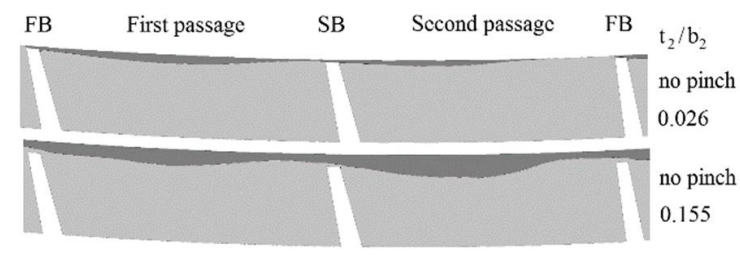

Fig. 13. Reversed flow and outflow areas at the impeller outlet with the largest and smallest tip clearances for the unpinched diffuser.

Dark grey is the reversed flow and light grey is the out coming flow.

flow is divided on either side of the splitter blade. The mass fractions entering the first and second passages remain constant when the tip clearance is increased. At all tip clearances, a slightly larger portion of the flow (approximately 52\%) goes into the first passage, and the flows entering the two channels are the same for each diffuser design.

When the flows entering and leaving the blade passages are compared, it can be seen that, with the unpinched diffuser, at the largest clearance the flows entering and leaving the blade passages are almost equal. At smaller clearances, there is more flow entering the first blade passage than leaving through the impeller exit and less flow entering the second passage than leaving through the impeller outlet. However, as the impeller must fulfil the continuation equation, the imbalance of mass flows must be due to the tip clearance flows.

\subsection{Reversed flow at the impeller outlet}

With the pinched diffusers, the tip clearance hardly affects the outgoing flow, which remains more or less constant for each passage when the clearance is increased (Fig. 8). However, with the unpinched diffuser the flow exiting the impeller from the first passage is increased and the flow leaving the second passage is

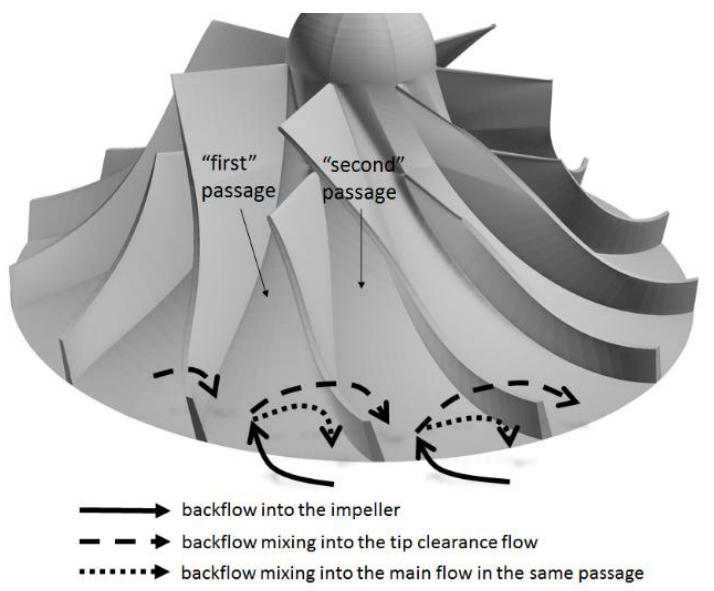

Fig. 12. An illustration of the reversed flow.

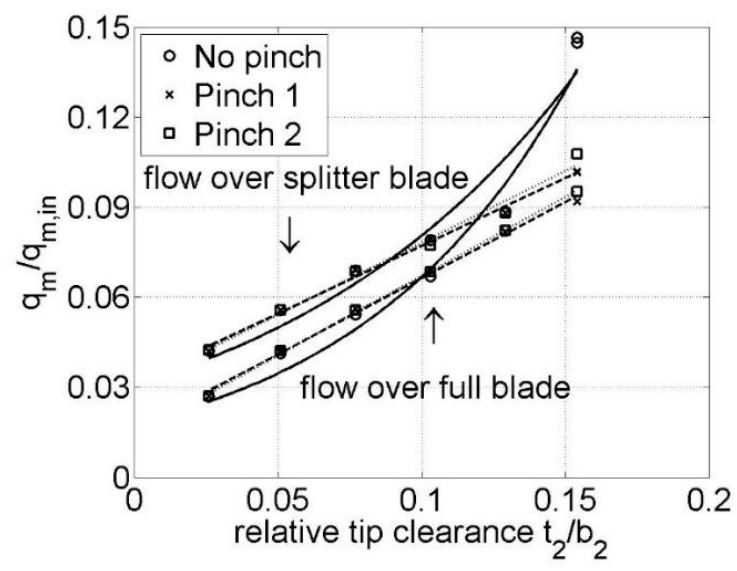

Fig. 14. Mass flows through the tip gaps.

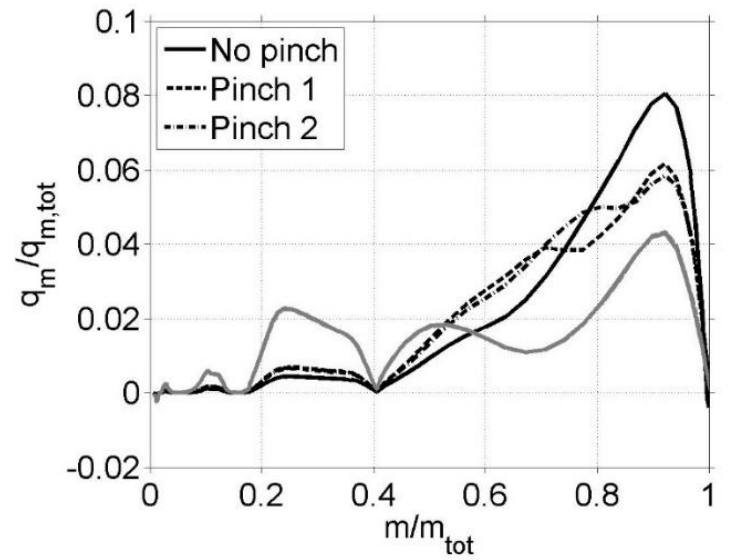

Fig. 15. Mass flow distribution over the full blade. Grey refers to the smallest tip clearance and black to the largest one. 


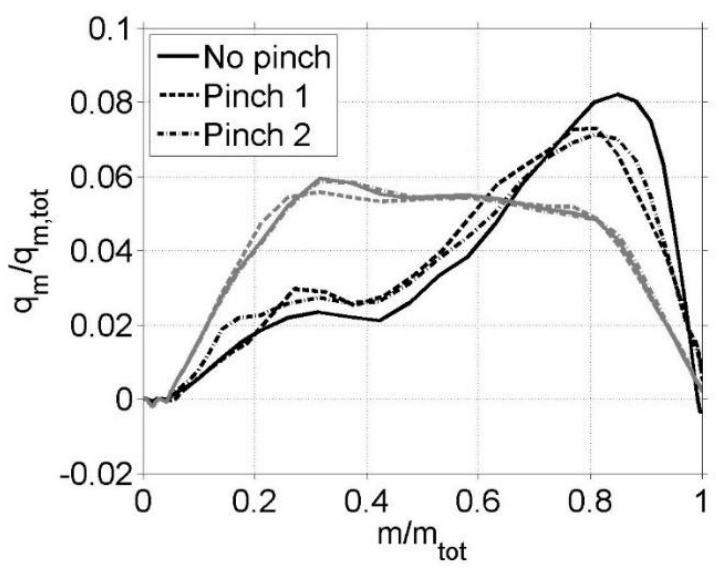

Fig. 16. Mass flow distribution over the splitter blade. Grey refers to the smallest tip clearance and black to the largest one.

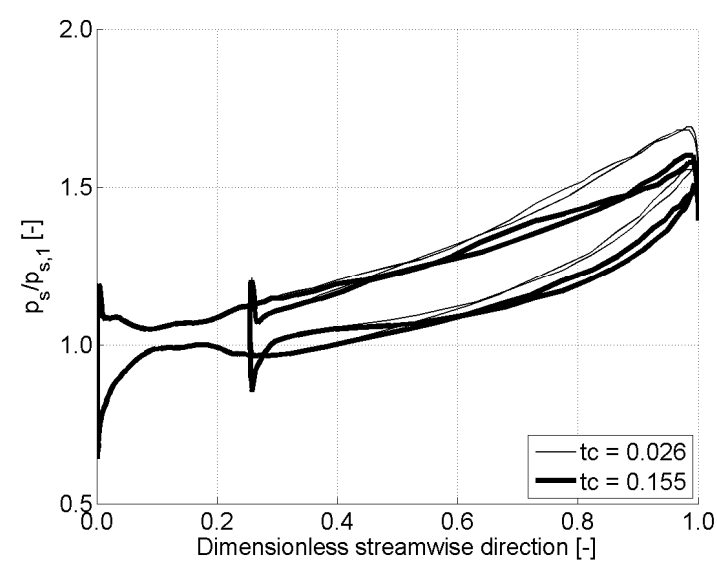

Fig. 18. Blade loading at the mid span with the smallest and largest clearances with the pinched 1 diffuser.

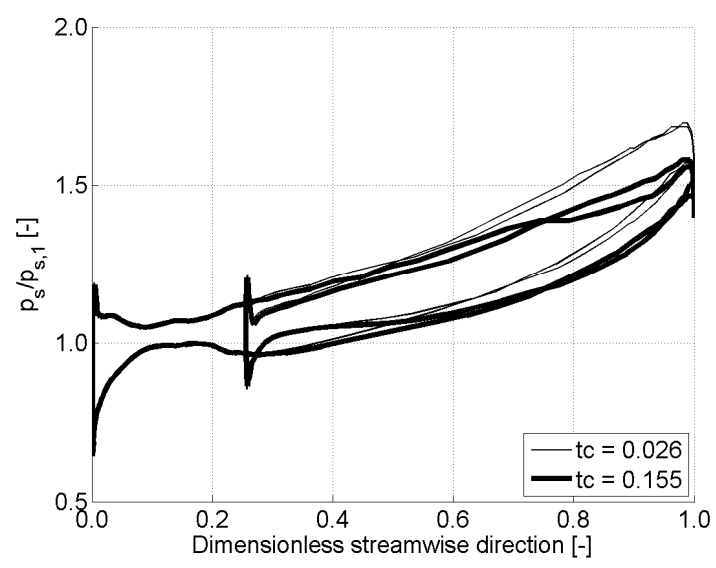

Fig. 17. Blade loading at the mid span with the smallest and largest clearances with the unpinched diffuser.

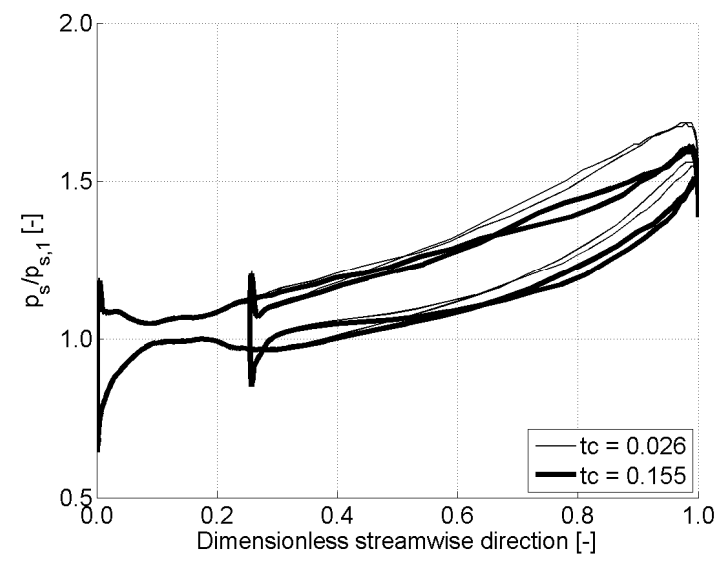

Fig. 19. Blade loading at the mid span with the smallest and largest clearances with the pinched 2 diffuser.

decreased as the tip clearance increases. At the largest tip clearance, the flow exiting the first channel equals the flow entering it, and the flow exiting the second channel equals the flow entering it.

A larger reversed flow region at the impeller outlet with the unpinched diffuser causes the trend. Reversed flow into the impeller as a function of the relative tip clearance is presented in Figs. 9 and 10 for the first and second passage, respectively. The reversed flow at the impeller outlet, especially in the second passage (Fig. 10), is increased due to increased tip clearance in the case of the unpinched diffuser. However, in the case of the pinched diffusers and with large tip clearances $\left(t_{2} / b_{2} \geq 10.3 \%\right)$, the pinch suppresses the reversed flow when compared to the unpinched diffuser. The suppression of reversed flow is one reason for the more uniform flow fields in the blade passages with large tip clearances due to the pinched diffuser.

Velocity vectors within the impeller with the unpinched diffuser and the largest tip clearance are shown in Fig. 11. The unpinched diffuser with the largest clearance is shown as it represents an extreme. It can be seen how part of the flow coming from the full blade leading edge remains on the full blade suction side and the remaining goes towards the splitter blade leading edge. From the splitter blade leading edge, the flow goes towards the next full blade pressure side. The quite large passage vortices are also clearly visible in both blade passages. 


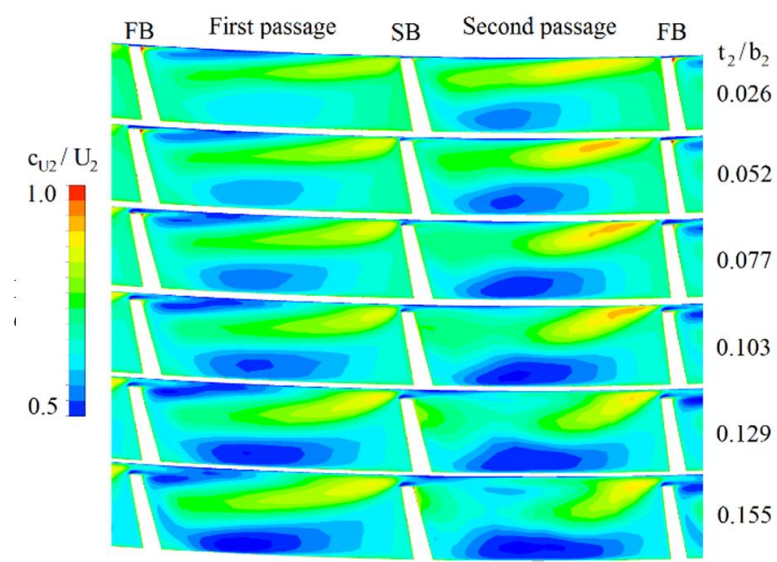

Fig. 20. Normalised tangential velocity at the impeller outlet with the unpinched diffuser and different tip clearances.

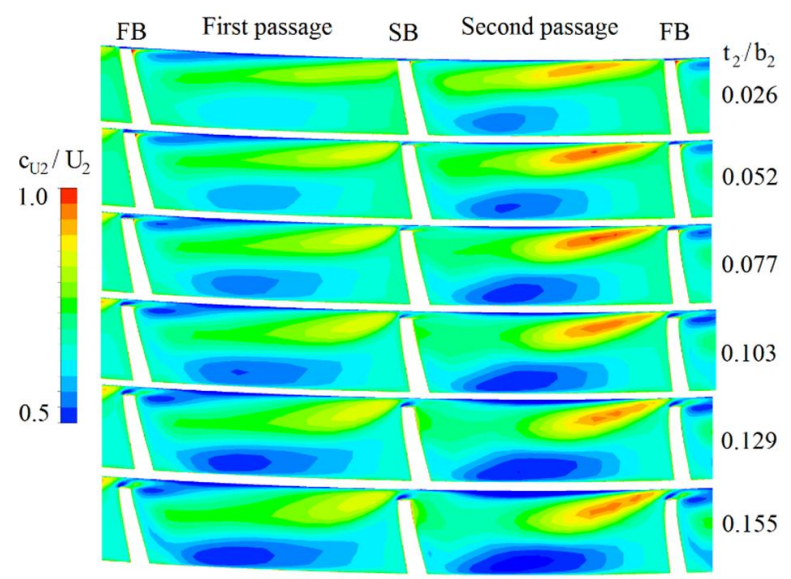

Fig. 22. Normalised tangential velocity at the impeller outlet with the pinched 2 diffuser and different tip clearances.

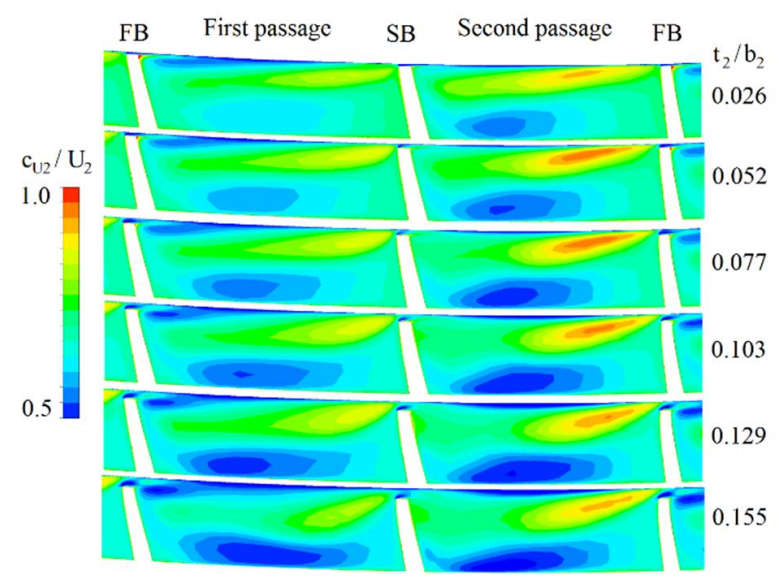

Fig. 21. Normalised tangential velocity at the impeller outlet with the pinched 1 diffuser and different tip clearances.

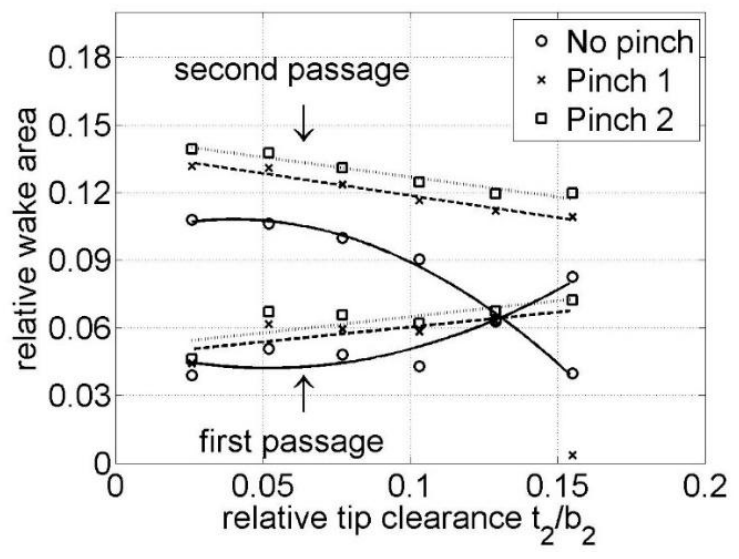

Fig. 23. Wake areas at the impeller outlet.

At both passage outlets, when the reversed flow enters the

impeller, part of the reversed flow is mixed into the jet in the same passage where the flow went back into the impeller. The mixing causes additional losses, and is increased when the tip clearance is increased. The portion of reversed flow which does not mix into the jet migrates over the blade and mixes into the tip clearance flow. In other words, reversed flow into the first passage partly mixes into the jet in the first passage, partly migrates over the splitter blade into the second channel, and mixes into the wake there and vice versa for the reversed flow into the second passage. An illustration of reversed flow is shown in Fig. 12.

With the unpinched diffuser, the reversed flow going into the second passage is increased more than reversed flow going into the first passage as the tip clearance is increased (Figs. 9 and 10). The difference is further highlighted in Fig. 13 where the reversed flow area and outflow area at the impeller outlet for the unpinched diffuser with the smallest and largest clearances are presented. The increase in the reversed flow in the second passage is due to a larger slow flow region which is partly caused by the stronger tip clearance flow.

\subsection{Tip leakage flow}

Mass flow over the full and splitter blades is shown in Fig. 14. In general, the tip clearance flow over the splitter blade is higher than the tip clearance flow over the full blade. The larger flow over the splitter blade partly explains why the adverse effects of 


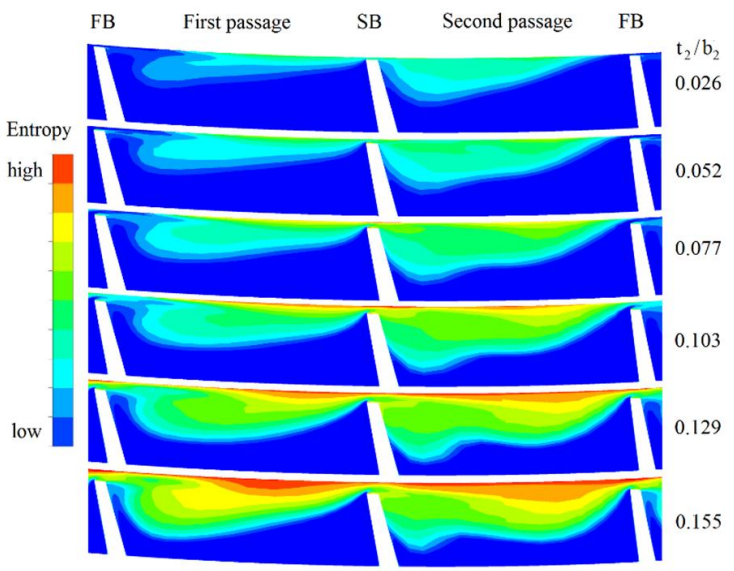

Fig. 24. Entropy at the impeller outlet with the unpinched diffuser and different tip clearances.

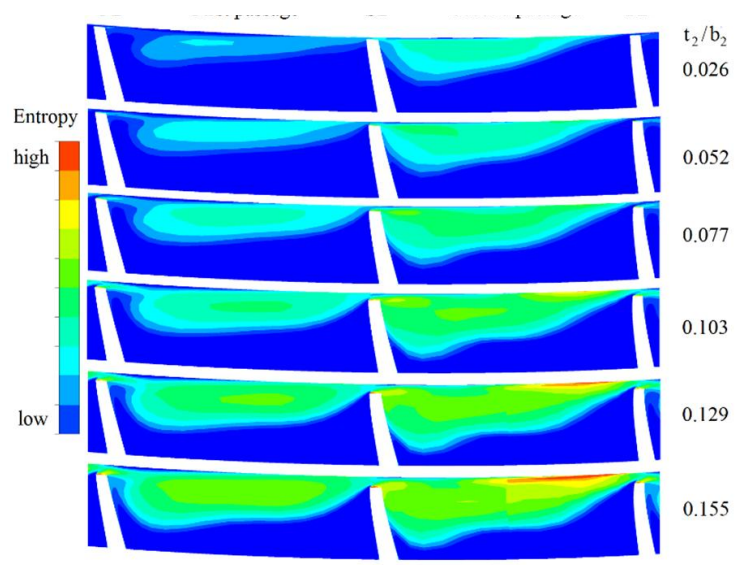

Fig. 26. Entropy at the impeller outlet with the pinched 2 diffuser and different tip clearances.

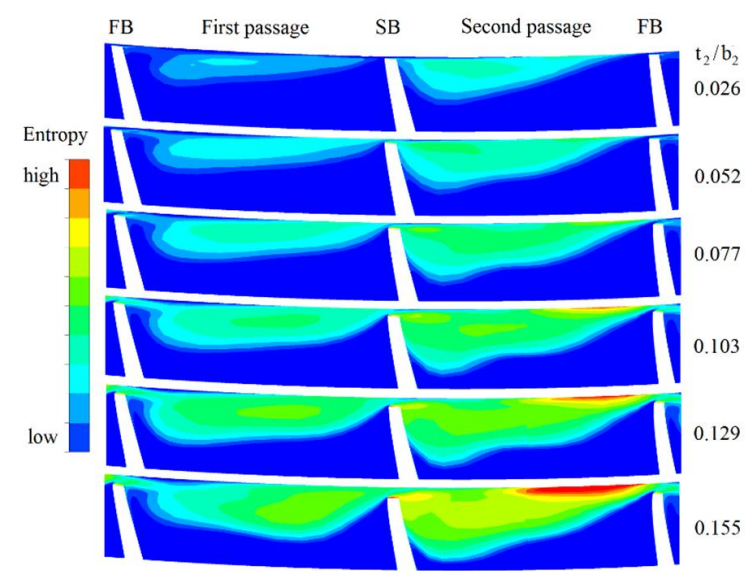

Fig. 25. Entropy at the impeller outlet with the pinched 1 diffuser and different tip clearances.
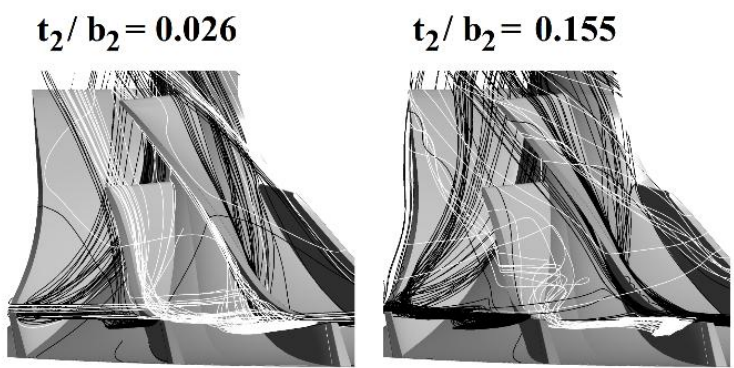

Fig. 27. Streamlines within the impeller with unpinched diffuser with the smallest (left) and largest (right) tip clearances.

the tip clearance are more severe on the suction side of the splitter blade, as observed in some previous studies $[10,14,16,17]$. Furthermore, in a previous study by the authors [17] it was concluded that part of the tip clearance flow over the full blade migrates over the splitter blade, hence partly explaining the increased flow over the splitter blade.

The flow over the blades increases as the tip clearance is increased. However, the difference between the flow going over the full blade and the flow going over the splitter blade decreases as the clearance is increased. Hence, the flow over the full blade increases more than the flow over the splitter blade. As concluded previously, the reversed flow into the second passage increases more than the reversed flow into the first passage, and part of the reversed flow migrates over the adjacent blade. Therefore, as the reversed flow is increased more in the second passage, the portion of flow over the full blade which originates from the reversed flow is increased more than that of the splitter blade, as the clearance is increased.

The effect of the tip clearance on the actual tip flow seems to be more complex than originally thought. At first, the mass flow over the blades seems to increase linearly, but in the case of the largest tip clearance without pinch the mass flows over the full and splitter blades are 1.5 times higher than those with pinch (Fig. 14). Therefore, it seems that the effect of the tip clearance on the tip leakage flow is not linear and the pinches are able to decrease the tip leakage flow by $35 \%$ in the case of the largest tip clearance.

The flow entering the first passage is constant with respect to the tip clearance, and at all tip clearance ratios, the flow over the 
splitter blade is higher than the flow over the full blade. Therefore, the flow exiting the first passage must be less than the flow entering the first passage, and vice versa for the second passage, as can be seen in Figs. 7 and 8.

Mass flow distributions over the full and splitter blades as a function of the relative meridional distance are shown in Figs. 15 and 16, respectively. Only the smallest (marked by grey lines) and largest (marked by black lines) tip clearances are shown in figures for the sake of clarity. With the smallest clearance there is hardly any difference (all the grey lines overlap in Fig. 15) in the flow distributions over the blades between the different diffusers, and flow over the full blade in the inducer before the splitter blade leading edge stays constant for all the diffusers. It should be noted that the radial clearance near the leading edge remained constant; hence, the mass flow over the blade should be constant there.

The tip leakage flow over the blades is increased in the aft-part of the impeller, where the tip clearance is increased relatively more than in the inducer. The pinched diffusers decrease the tip leakage flow near the blade trailing edge in the case of the largest tip clearance $\left(t_{2} / b_{2}=15.5 \%\right)$. A similar effect of the pinched diffusers is also visible in the case of the splitter blade (Fig. 16), but the decrease in tip leakage flow is not as strong. In literature, there are some suggestions that fore-loaded impellers are not as sensitive to clearance effects as the aft-loaded impellers [11], and the distribution of leakage flow might be a reason for it.

The blade loading at the mid span with the smallest and largest tip clearances for the three diffusers are shown in Figs. 17-19. The two extremes are presented for convenience, the other clearances fall in between the minimum and maximum in a good agreement. Blade loading decreases mostly in the impeller with unpinched diffuser. The peak value of blade loading decreases $6.2 \%$ in average (the largest decrease of $7.5 \%$ on the full blade pressure side) in the impeller with unpinched diffuser, whereas the mean decrease in peak blade loading is 4.6 and $4.1 \%$ in impellers with pinched 1 and pinched 2 diffusers, respectively.

There is no significant effect of pinched diffuser on blade loading with the smallest tip clearance (pinched diffusers decrease peak blade loading by $0.5 \%$ in average). However, pinched diffusers increase peak blade loading by $1.2 \%$ with pinched 1 diffuser and $1.7 \%$ with pinched 2 diffuser, in average. The pinched diffuser affects mostly on the full blade pressure side.

\section{Flow fields}

Pinch does not affect the mass flow over the blades in the inducer as showed in Fig. 15. The differences in the flow fields due to pinch are visible in the last $30 \%$ of the impeller. Hence, the investigation is limited near the trailing edge. In general, pinches make the flow field more uniform at the impeller outlet by attenuating the reversed flow in the second passage. Without the pinch, there would be $45 \%$ more reversed flow in the second passage than in the first one.

Tangential velocity distributions at the impeller outlet are presented in Figs. 20-22. The pinches make the flow field more uniform in the first passage, but in the second one the flow field seems to be less uniform: wake is increased and intensified. To study the wake in more detail, the wake areas are investigated. In order to do so, the wake must be defined. Here, a flow area is considered as wake if the tangential velocity compared to the impeller tip speed is equal to or greater than $0.8\left(c_{\mathrm{u}} / U_{2} \geq 0.8\right)$. Wake areas at the impeller outlet are shown in Fig. 23.

In general, the wake is larger in the second passage than in the first passage, irrespective of the diffuser. Furthermore, wakes are larger with the pinched diffuser than with the unpinched one. When the tip clearance is increased, the general trend is that the wake area decreases in the second passage and increases in the first passage. The effect is more pronounced with the unpinched diffuser. As mentioned earlier, at lower clearances there is a surplus of mass flow in the second passage and a deficit in the first passage. The difference in the flows entering the blade passages and exiting them through the impeller outlet evened out as the clearance was increased as the flow over the full blade increased more than flow over the splitter blade. The changes in the mass balance are seen in the wake area at the impeller outlet. As the surplus of mass in the second passage is decreased, the wake area is reduced, and similarly in the first passage. As the deficit is reduced, the wake area is increased.

As it was already shown in Figs. 15 and 16, the pinch decreases the tip leakage flow near the blade trailing edge more over the full blade than over the splitter blade. In other words, the pinches are able to attenuate the reversed flow in the second passage, which results in the decreased tip leakage flow over the full blade.

Entropy distributions at the impeller outlet are shown in Figs. 24-26. When the pinch is implemented, the entropy is lower at the impeller outlet and the effect is more profound at higher tip clearances. The pinches reduce entropy in both passages. Even though the pinches increased the tangential velocity region at the impeller outlet in the second passage (strengthened the wake there), they reduced the entropy generation also in the second passage. For example with the largest clearance, the larger pinch reduced entropy at the impeller outlet approximately $30 \%$ in both passages.

The flow over the tip clearance with the unpinched diffuser is illustrated with streamlines in Fig. 27 where the streamlines within the impeller are shown with the highest and lowest tip clearance. The streamlines are shown for only one diffuser, as the behaviour is similar even if the pinch is implemented. As the clearance is increased the clearance flow over the splitter blade mixes into the low meridional velocity flow present at the suction side. As the clearance flow mixes into the low meridional 
velocity flow, the entropy increases there (Figs. 24-26). At the same time, less clearance flow migrates to the pressure side of the full blade, resulting in increase in the tangential velocity there.

\section{Conclusions and discussion}

This study numerically examines the effect of tip clearance on the flow fields in a centrifugal compressor impeller. The impeller is coupled with three different vaneless diffusers, varying in diffuser width. The vaneless diffusers are an unpinched one, one with a $10 \%$ width reduction, and one with a $15 \%$ width reduction. Each of the three designs were modelled with six different relative tip clearances. The modelled relative tip clearances $t_{2} / b_{2}$ were between 0.026 and 0.155 . The tip clearance is changed by transposing the shroud side wall in the axial direction. Hence, the largest changes in the tip clearance are seen at the impeller outlet, whilst the radial clearance at the leading edge remains constant.

The main findings of the work can be summarised as follows:

- The changes in tip clearance did not affect how the mass flow was divided by the splitter blade. At all clearances, roughly $52 \%$ of the flow entered the passage between the full blade suction side and splitter blade pressure side. However, the clearance at the splitter leading edge doubled when the clearance was changed from the minimum to the maximum. Therefore, it seems that the radial clearance at the inducer is less dominant than the axial clearance at the trailing edge.

- Mass flow over the splitter blade was larger than the flow over the full blade at all clearances. Hence, flow exiting the passage between the full blade suction side and splitter blade pressure side was smaller than flow entering it, and vice versa for the other passage.

- With the pinched diffusers, the reversed flow into the impeller increased linearly and there were no substantial differences between the reversed flows into the two passages when the tip clearance increased. However, with the unpinched diffu ser the reversed flow into the impeller increased exponentially. Furthermore, the reversed flow increased substantially more in the passage between the splitter blade suction side and full blade pressure side. In addition, the flow over the full blade increased more than the flow over the splitter blade. As the reversed flow enters the blade passage, part of it is mixed into the main flow in the same passage as it went back into the impeller, and the rest migrates over the adjacent blade and mixes into the flow there.

- The reversed flow increased more in the blade passage between the suction side of the splitter blade and pressure side of the full blade. The reversed flow there increases more because 1) as known from the literature, the adverse effects of the tip clearance are more severe on the suction side of the splitter blade, 2) the mass flow over the splitter blade is larger than flow over the full blade, and 3) as the wake is larger on the suction side of the splitter blade to begin with, the reversed flow area and reversed flow increases more in the second passage.

- The pinch hardly affected the wake in the blade passage between the full blade suction side and splitter blade pressure side, and increased it in the other passage. However, the pinches decreased the entropy at the impeller outlet in both passages. With the unpinched diffuser, the wake becomes weaker as the clearance is increased because the clearance flow is mixed into it. As the pinch reduces the reversed flow and also the flow over the blades closer to the trailing edge, the wake remains stronger. However, as a net result the pinches used in this study decreased losses.

- The wakes were larger with pinches than without them. However, the entropy at the impeller outlet was smaller with pinches than without them, indicating fewer losses. Based on previous studies, the pinches used in this study improved compressor efficiency. It is evident that pinch decreases the reversed flow at the impeller outlet. The reversed flow increases the tip clearance flow, which then mixes into the wake, weakening it. As the pinches prevent this the wakes are larger but the losses are smaller.

All in all, there seems to be quite strong interaction between the reversed flow at the impeller outlet, present in unshrouded impellers and the tip clearance flow. The two are coupled in such a way that when the clearance is increased, the clearance flow increases the reversed flow into the impeller, which in turn increases the clearance flow, and so on. The results indicate that the effect of the tip clearance on the flow over the blades and the reversed flow is non-linear. With an unpinched diffuser, both seemed to grow exponentially.

In the future, the effect of radial clearance should be studied, or both the radial and axial clearances should be increased (i.e. keeping the clearance constant over the meridional length). Furthermore, as there seems to be an interaction between the reversed flow and tip clearance flow, the unsteady effects might be beneficial to study. In addition, the circumferential location and the leading edge location of splitter blades must be studied further, as part of the observed phenomena might be due to the flow dividing unevenly into the two passages. 


\section{Acknowledgment}

The authors gratefully acknowledge the financial contribution of the Academy of Finland, under the grant number 274897.

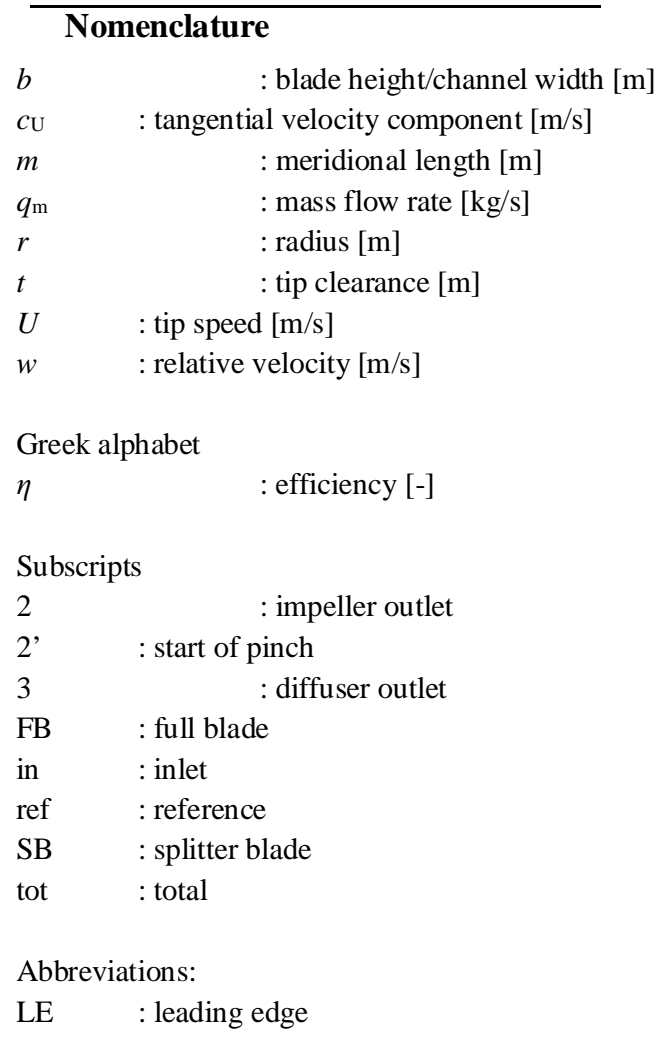

\section{References}

[1] de Almeida A, Fonseca P, Falkner H and Bertoldi P. Market Transformation of Energy-Efficient Motor Technologies in the EU. Energy Policy 2003; 31:563-575.

[2] Saidur R, Rahim N and Hasnuzzaman M. A Review on Compressed-Air Energy Use and Energy Savings. Renewable and Sustainable Energy Reviews. 2010; 14:1135-1153.

[3] Viholainen J, Grönman K, Jaatinen-Värri A, Grönman A, Ukkonen P and Luoranen M. Centrifugal Compressor Efficiency Improvement and Its Environmental Impact in Waste Water Treatment. Energy Conversion and Management. 2015; 101:336342.

[4] Pampreen R. Small Turbomachinery Compressor and Fan Aerodynamics. Journal of Engineering for Gas Turbines and Power. 1973; 95:251-256.

[5] Eisenlohr G and Chladek H. Thermal Tip Clearance Control for Centrifugal Compressor of an APU Engine. Journal of Turbomachinery. 1994; 116:629-634.

[6] Palmer D and Waterman W. Design and Development of an Advanced Two-Stage Centrifugal Compressor. Journal of Turbomachinery. 1995; 117:205-212.

[7] Turunen-Saaresti T and Jaatinen A. Influence of the Different Design Parameters to the Centrifugal Compressor Tip Clearance Loss. Journal of Turbomachinery. 2013; 135:011017.

[8] Backman J, Reunanen A, Saari J, Turunen-Saaresti T, Sallinen P and Esa H. Effects of Impeller Tip Clearance on Centrifugal Compressor Efficiency. Proceedings of ASME Turbo Expo, 2007, Montreal, Canada, May 14-17, 2007, paper no. GT2007-28200.

[9] Denton J. Loss Mechanisms in Turbomachines. Journal of Turbomachinery. 1993; 115:621-656.

[10]Schleer M, Song SJ, and Abhari RS. Clearance Effects on the Onset of Instability in a Centrifugal Compressor. Journal of Turbomachinery. 2008; 130:031002.

[11]Zangeneh M, Schleer M, Pløger F, Hong SS, Roduner C, Ribi B and Abhari RS. Investigation of an Inversely Designed Centrifugal Compressor Stage - Part I: Design and Numerical Verification. Journal of Turbomachinery. 2004; 126:73-81. 
[12]Ishida M, Senoo Y and Ueki H. Secondary Flow Due to the Tip Clearance at the Exit of Centrifugal Impellers. Journal of Turbomachinery. 1990; 112:19-24.

[13]Buffaz N and Trébinjac I. Detailed Analysis of the Flow in the Inducer of a Transonic Centrifugal Compressor. Journal of Thermal Science. 2002; 21:1-12.

[14]Schleer M and Abhari RS. Clearance Effects on the Evolution of the Flow in the Vaneless Diffuser of a Centrifugal Compressor at Part Load Condition. Journal of Turbomachinery. 2008; 130:031009.

[15]Schleer M, Hong SS, Zangeneh M, Roduner C, Ribi B, Pløger F and Abhari RS. Investigation of an Inversely Designed Centrifugal Compressor Stage - Part II: Experimental Investigations. Journal of Turbomachinery. 2004; 126:82-90.

[16]Wang H-L, Xi G, Li J-Y and Yuan M-L. Effect of the Tip Clearance Variation on the Performance of a Centrifugal Compressor with Considering Impeller Deformation. Proceedings of the Institution of Mechanical Engineers, Part A: Journal of Power and Energy. 2011, 225:1143-1155, 2011.

[17]Jaatinen-Värri A, Grönman A, Turunen-Saaresti T and Backman J. Investigation of the Stage Performance and Flow Fields in Centrifugal Compressor with a Vaneless Diffuser. International Journal of Rotating Machinery. 2014, 2014; 139153.

[18]Bousquet Y, Carbonneau X, Trébinjac I, Dufour D and Roumeas M. Description of the Unsteady Flow Pattern from Peak Efficiency to Near Surge in a Subsonic Centrifugal Compressor Stage. In Proceedings of the 10th European Conference on Turbomachinery: Fluid Dynamics and Thermodynamics, 2013, pages 917-927, Lappeenranta, Finland, April 15-19, 2013.

[19]Tang J, Turunen-Saaresti T, Reunanen A, Honkatukia J and Larjola J. Numerical Investigation of the Effect of Tip Clearance to the Performance of a Small Centrifugal Compressor. In Proceedings of ASME Turbo Expo, 2006, Barcelona, Spain, May 8-11, 2006, paper no. GT2006-90893.

[20] Jaatinen A, Grönman A, Turunen-Saaresti T and Röyttä P. Effect of Vaneless Diffuser Width on the Overall Performance of a Centrifugal Compressor. Proceedings of the Institution of Mechanical Engineers, Part A: Journal of Power and Energy. 2011; 225:665-673.

[21]Jaatinen A, Turunen-Saaresti T, Grönman A, Röyttä P and Backman J. Experimental Study of the Effect of the Tip Clearance to the Diffuser Flow Field and Stage Performance of a Centrifugal Compressor. In Proceedings of ASME Turbo Expo, 2012, Copenhagen, Denmark, June 11-15, 2012, paper no. GT2012-68445.

[22]Jaatinen-Värri A, Röyttä P, Turunen-Saaresti T and Grönman A. Experimental Study of Centrifugal Compressor Vaneless Diffuser Width. Journal of Mechanical Science and Technology. 2013; 27:1011-1020.

[23]Jaatinen-Värri A, Turunen-Saaresti T, Röyttä R, Grönman A and Backman J. Experimental Study of Centrifugal Compressor Tip Clearance and Vaneless Diffuser Flow Fields. Proceedings of the Institution of Mechanical Engineers, Part A: Journal of Power and Energy. 2013; 227:885-895.

[24]Jaatinen-Värri A, Turunen-Saaresti T, Grönman A, Backman J and Tiainen J. Numerical Investigation of Centrifugal Compressor Tip Clearance. In Proceedings of ASME Turbo Expo, Montreal Canada, June 15- 19, 2015, paper no. GT2015-43199.

[25]Oh J and Agrawal GL. Numerical Investigation of Low Solidity Vaned Diffuser Performance in a High-Pressure Centrifugal Compressor, Part I: Influence of Vane Solidity. In Proceedings of ASME Turbo Expo, 2007, May 14-17, 2007, Montreal, Canada, paper no. GT2007-27260.

[26]J. Oh, C. W. Buckley, and G. L. Agrawal. Numerical Investigation of Low Solidity Vaned Diffuser Performance in a High-Pressure Centrifugal Compressor, Part II: Influence of Vane Stagger. In Proceedings of ASME Turbo Expo, 2008, June 9-13, 2008, Berlin, Germany, paper no. GT2008-50178. 